\title{
Research on General Electric Organizational Structure Reform Based on Hofstede's Cultural Dimension Theory
}

\author{
Fan Dongxuan ${ }^{1, *}$ \\ ${ }^{1}$ School of Economics and Management, Beijing Jiaotong University, Beijing 100044, China \\ *Corresponding author.Email:19120735@bjtu.edu.cn
}

\begin{abstract}
General Electric Company is the world's largest multinational company that provides technology and service business. This article first sorts out the reform of the organizational structure of General Electric Company. Then, based on the cultural dimension theory of Hofstede, we make an analysis of the internal organizational structure reform of General Electric Company from the power distance, uncertainty avoidance, short-term orientation - the long-term orientation dimensions. Finally, we find that General Electric Company gradually clarifies the core business of the enterprise to realise a flat organization structure with lower power distance, stronger uncertainty avoidance and stronger long-term orientation. General Electric 's organizational structure reform provides a reference for the organizational structure management of enterprises all over the world. Keywords: Hofstede's cultural dimensions theory, organizational strategy management, General Electric
\end{abstract}

\section{INTRODUCTION}

General Electric Company (GE) is the world's largest diversified service company. Since its establishment in 1892, the company is committed to creating a better life through multiple technologies and services. GE 's products and services range from aircraft engines, power generation equipment, water treatment and safety technologies, to medical imaging, commercial and consumer finance, media content and industrial products. After World War I, GE took the absolute lead in radio. When the World War II broke out, GE was no longer satisfied with its dominance in the electrical industry. Instead, it took the opportunity of war to get involved in military manufacturing fields such as aircraft and ships. Since then, GE has slowly eroded many domestic and foreign companies, and gradually developed into a huge multinational company. As an old American company with a history of nearly 130 years, GE is famous for its efficient and flexible organizational structure. This article uses Hofstede 's cultural dimension theory to analyse the development and evolution of GE's organizational structure in the process of development and management, providing references for enterprises in various countries.

\section{HOFSTEDE'S CULTURAL DIMENSION THEORY AND REFORM OF CORPORATE ORGANIZATIONAL STRUCTURE}

\subsection{Hofstede's Cultural Dimension Theory}

In order to distinguish the cultural characteristics of different countries, Dutch sociologist Gilt Hofstede conducted a survey of more than 100,000 employees from more than 40 countries employed by the large multinational company IBM from 1967 to 1973, and thus put forward the innovative analysis of the five dimensions of cultural differences in different countries: power distance, uncertainty avoidance, individualismcollectivism, masculinity-femininity, long-term orientation -short-term orientation, forming a theoretical framework of cultural five dimensions [1]. The theory is widely used in interdisciplinary theoretical research and intercultural communication practice [2]. The specific definition is shown in Table 1. 
Table 1 Five dimensions of Hofstede's cultural dimensions theory

\begin{tabular}{|c|l|}
\hline Cultural dimension & \multicolumn{1}{c|}{ Definition } \\
\hline Power distance & $\begin{array}{l}\text { Acceptance of a low social status of people for unequal } \\
\text { distribution of power in society or an organization. }\end{array}$ \\
\hline Uncertainty avoidance & $\begin{array}{l}\text { The extent to which you feel threatened in the face of } \\
\text { uncertain or unknown situations, or to what extent you try to } \\
\text { avoid uncertain situations by means of technology, law, } \\
\text { religion, etc. }\end{array}$ \\
\hline $\begin{array}{c}\text { Individualism- } \\
\text { collectivism }\end{array}$ & $\begin{array}{l}\text { Measure whether a society as a whole focuses on individual } \\
\text { interests or collective interests. }\end{array}$ \\
\hline Masculinity-femininity & $\begin{array}{l}\text { See if a society represents more male qualities such as } \\
\text { competitiveness and arbitrariness, or represent female } \\
\text { qualities such as modesty, caring more about others, and the } \\
\text { definition of male and female functions. }\end{array}$ \\
\hline $\begin{array}{c}\text { Long-term orientation - } \\
\text { short-term orientation }\end{array}$ & $\begin{array}{l}\text { The extent to which delays in meeting their material, } \\
\text { emotional, and social needs are acceptable. }\end{array}$ \\
\hline
\end{tabular}

\subsection{The Application of Cultural Dimension Theory in the Reform of Corporate Organizational Structure}

Hofstede's cultural dimension theory was originally designed to manage human resources, but with the continuous development of social economy, it is now more used in the organization and management of enterprises [3]. Among them, the corporate organizational structure is an extremely important part. It refers to the internal structure of the organization and the interrelationship between organizations in order to achieve the goals of the organization. To a large extent, the competitive advantage of an enterprise comes from the internal operating mechanism of the organization. A reasonable organizational structure can form the aggregation and amplification effect of the overall power. By optimizing the elements combination, resource utilization, and operation process, the efficiency synergy among the elements of the enterprise can be achieved.

Nowadays enterprises are carrying out organizational forms from linear system and functional system gradually moving towards flat, networked, borderless, diversified systems. However, Hofstede's cultural dimension theory provides a new perspective to analyse corporate organizational structure changes. In the five dimensions, the power distance can most intuitively reflect the changes in the organizational structure of the enterprise. The smaller the power distance means the more flexible, efficient and flat organizational structure, which is realized from the original "vertical pyramid structure". Actually this transformation enhances the enterprises' dynamic response and coordination capabilities. In addition, the features of weak uncertainty avoidance, individualism, and short-term orientation will also promote the formation of a corporate culture that advocates innovation and selfexpression, thereby forming a more decentralized and flexible organizational structure.

\section{GENERAL ELECTRIC'S ORGANIZATIONAL STRUCTURE REFORM}

In order to release and explore the enterprise's scientific and technological innovation efficiency, GE has successively carried out a far-reaching efficiency-type centralized functional organizational structure and an innovative divisional and decentralized organizational structure to build professional management with excellent innovation governance capabilities system [4]. In the early stage of establishment, GE's continuous expansion of business scale led to the complexity of the company's operations, and the functional organizational structure constituted an institutional obstacle to diversified operations and continuous innovation [5]. The transformation process of GE's organizational structure is shown in Figure 1.

In the early 1940s, President Gerald Swarp began to plan the decentralization reform of organizational management, based on technology and market, to enhance the innovation performance of various diversified business departments. In 1953, President Ralph Cordiner formally implemented decentralization reforms, establishing multiple business divisions of diversified business innovation organizations and splitting the company into 150 departments, independent of each other. In 1970, President Fred Borch built a more innovative strategic management system-"Strategic Division". President Reggie Jones strengthened R\&D efforts to develop longterm scientific and technological innovation strategy and established "Super Division" system organizational structure.

In the 1980s, GE faced "big enterprise diseases" such as bloated institutions, multiple levels, complicated procedures, serious bureaucracy, and unresponsiveness. At the same time, it had problems of "excessive diversification". President Jack Welch started "creative destruction" after taking office, he transformed strategic thinking, compressed management levels, broke department boundaries, and gave play to people's initiative. Welch cleared core business, focusing on traditional manufacturing, high technology and services. Through frequent mergers and reorganizations, he implemented of the "one of the best" strategy that company should be either 1 or 2 in a particular industry, or else leave it completely. In 2001, after Jeffrey R. Immelt took over as president, he drastically adjusted the company's business portfolio, divested non-core businesses, concentrated resources for the innovation and development of growth engines, and established five key markets with power generation, aviation, transportation, medical treatment and oil \& gas. 


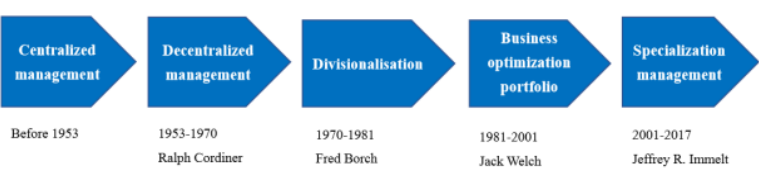

Figure 1 General Electric organizational structure reform

\section{GENERAL ELECTRIC'S APPLICATION OF HOFSTEDE'S CULTURAL DIMENSION THEORY}

As a large and diversified enterprise in the United States, GE's development is inseparable from the scientific and forward-looking perspective of organizational structure management. With the changes in corporate strategic goals and external environment, GE has adjusted and reformed its organizational structure, strengthened the effective coordination of various functional forces, and enhanced the efficiency of corporate operations. Here, Hofstede's cultural dimension theory is used to analyse it from three dimensions: power distance, uncertainty avoidance, and long-term orientation.

\subsection{Lower power distance}

It can be seen from Figure 1 that GE's organizational structure has generally undergone the development process from centralized operation to decentralized operation to professional management, which also reflects the change in power distance within GE. According to Hofstede's theory, the power distance will be more obvious in the organizational structure. Organizations with high power distances generally have distinct hierarchies, while organizations with low power distances are generally flat. From the perspective of decision-making methods within organizations, organizations with large power distances tend to adopt top-down decision-making methods, and organizations with small power distances tend to adopt bottom-up decision-making methods which contribute to absorbing bottom-level opinions. The main comparison is shown in Table 2.

Table 2 Comparison of corporate power distance characteristics

\begin{tabular}{|c|c|c|}
\hline Characteristic & High power distance & Low power distance \\
\hline Organizational structure & distinct hierarchies & flat structure \\
\hline Decision-making method & top-down & bottom-up \\
\hline Information flow & unidirectional flow & free flow \\
\hline Organizational efficiency & low efficiency & high efficiency \\
\hline
\end{tabular}

The power distance of GE is gradually decreasing with the change of its organizational structure, which also means that its organizational structure tends to be more flattened, thus forming a free flow of information and more efficient organizational structure and corporate culture.
Take Jack Welch's organizational reform as an example, which has been called the largest organizational reform in GE's history. In the 1980s, Welch used the "Work-Out" strategy to reduce unnecessary bureaucracy and the power distance within the organization to speed up the product development process of each department and improve the organization's operating process. It also eliminated unnecessary work and allowed information to flow freely, thereby improving the value creation efficiency of the entire business process. In addition, Welch advocated extensive mutual learning among employees, departments, and regions, and proposed borderless behaviour to reduce the management level. Meanwhile, Welch created the "hearing" system to further reduce the power distance, which allowed ordinary employees to participate in the management of the company. In the 1990s, Welch officially implemented the Six Sigma plan to improve product quality and optimize the enterprise quality process management mechanism, which greatly improved GE's organizational efficiency. It can be seen that the reduction of the power distance of the enterprise, which is brought by the flattening of GE's organizational structure, reduces the management level of the enterprise and creates a more flexible and creative organizational atmosphere and corporate culture.

\subsection{Stronger Uncertainty Avoidance}

In general, the uncertainty avoidance in the United States is relatively weak because of the adventurous spirit advocated by the United States. People are willing to accept and dare to face the uncertainties in life. But in the entire organizational change process of GE, we can see that its degree of uncertainty avoidance has increased.

Before the 1950s, GE was huge and involved a variety of businesses, but its power was concentrated in its headquarters in New York, and its net profit was low, and centralized operations were no longer suitable for the company's development. Later, in order to reduce the risk of "big business disease", GE began to implement decentralized reforms, and decided to adopt a business unit system according to different business categories, or even a "super business unit system", and set up a "strategic business unit" within the business unit to be able to selectively manage certain products or businesses. Based on that, the business department could flexibly and effectively allocate human and material resources to use, and compile a rigorous and predictable strategy for various products, sales, equipment and organizations plan. In the 1980s, GE's "excessive diversification" problem was serious. In order to clarify the core of the business, GE adopted the "one of the best" strategy to focus on traditional manufacturing, high technology and services to reorganize and streamline the organization. 


\subsection{Stronger Long-term Orientation}

For a long time, GE has mainly operated industrial equipment and household appliances. After Welch took office in 1981, he believed that GE did not have a chance to compete with Japanese companies in the manufacturing field. It has gradually moved away from traditional manufacturing by selling manufacturing businesses such as small household appliances, semiconductors and mobile communications, and buying companies related to finance, television broadcasting and medical devices [6].

But since the 1990s, the environment of the industry has undergone major changes, and all industries have gradually begun to change with the development of digital technology. After Jeffrey R. Immelt took office, he rethought the strategic goals of the enterprise from a longterm and strategic perspective. In 2012, he first proposed the concept of "Industrial Internet" and believed that all businesses that cannot be in contact with customers should be digitized or outsourced. Subsequently, GE made great efforts to promote the digital transformation. In 2015, GE reorganized its organizational structure and integrated all digital functions into a unified digital business unit, GE Digital Department, to further shorten the organizational chain to optimize efficiency and focus on industrial machinery. GE makes strategic layout of the enterprise's long-term development plan which is based on the external environment and changes in future development trends. The digital manufacturing transformation fully reflects GE's long-term orientation.

\section{CONCLUSION}

Based on Hofstede's cultural dimension theory, this paper analyses the reform and evolution of the organization structure of General Electric Company. GE's organizational structure has generally gone through the development process from centralized operation to decentralized operation to professional management with lower power distance, stronger uncertainty avoidance and stronger long-term orientation. GE focuses on solving the problem of "excessive diversification" and gradually clarifies the core business of the enterprise to realise a flat organization structure. Specifically, this kind of organization structure enhances the enterprise's operational efficiency, strengthens effective collaboration among various departments, promotes the growth of effective resources, and ultimately promotes the healthy development of the enterprise. At the same time, GE actively predicts and adapts to the future economic development situation, taking the lead in formulating forward-looking corporate development strategies. And it also attaches importance to long-term orientation and efficiently collaborates with corporate organizational structures and strategic goals.

If enterprises want to achieve their own stable and sustainable development, they must attach great importance to whether their organizational structure can efficiently serve their organizational strategy. As an industrial giant, General Electric applies Hofstede's cultural dimension theory to the practice of enterprise management, focusing on the dynamic adjustment of the internal organizational structure and strategy, which provides references for the organizational structure management of enterprises around the world.

\section{REFERENCES}

[1] Hofstede, G., Hofstede, G.J. and Minkov, M. (2010) Cultures and Organizations: Software for the Mind, Third Edition. McGraw-Hill Education, New York.

[2] Li W.J. (2009) Hofstede's Cultural Dimension and Intercultural Studies. Journal of Social Sciences, 12:126$129+185$.

[3] Wang J, Qin A.J. (2012) An Analysis of the Cultural Management of Multinational Companies_-Guided by Hofstede's Cultural Dimension Theory. People's Tribune, 26:184-185.

[4] Yang Z.H. (2016) The Historical References of Innovation-Driven Strategy from General Electric Company. Commercial Research, 05:106-110.

[5] Yang Z.H. (2016) The Theoretical and Empirical Analysis on the Enterprise' Innovating Mechanism-A Case of GE. Science and Technology Management Research, 36(06):151-158.

[6] Nakata A. (2018) Revolution (Digital Transformation of GE). China Machine Press, Beijing. 